\title{
Diálogos Com a Matemática Na EdUCAÇÃo INFANTIL: POSSIBILIDADES DE APRENDIZAgeM COM A PEDAGOGIA FreINET
}

\author{
DIALOGUES WITH MATHEMATICS IN EARLY CHILDHOOD EDUCATION: \\ LEARNING POSSIBILITIES WITH FREINET PEDAGOGY
}

DOI: 10.23926/RPD.2526-2149.2020.v5.n2.p652-672.id715

\author{
Evandro Tortora \\ Doutor em Educação para \\ Ciência (UNESP) \\ Professor de Educação \\ Infantil da Rede Municipal \\ de Campinas. \\ evandro.tortora@unesp.br
}

Resumo: Esta pesquisa descreve os percursos e aprendizagens de crianças da Educação Infantil nos seus tateamentos experimentais envolvendo conhecimentos matemáticos. O objetivo deste estudo é responder ao seguinte problema de pesquisa: "Quais vivências podem ser planejadas para a aprendizagem de conceitos matemáticos na Educação Infantil dentro de pressupostos da Pedagogia Freinet?”. Para os estudos, fez-se uso dos referenciais teóricos de Pedagogia Freinet, como Freinet (1996), Sampaio (2006) e da Educação Matemática, como Lorenzato (2008) e Smole (2003). A metodologia de pesquisa utilizada foi a pesquisa-ação. Os resultados apontam que intervenções planejadas conseguiram criar contextos ampliados para aprendizagem de matemática resultando em aprendizagens que se fizeram presentes em brincadeiras e interações entre as crianças durante as rotinas da turma como pular-corda, brincar de amarelinha, jogos matemáticos, utilização de mapas da sala e registros de contagens.

Palavras-chave: Educação Infantil. Educação Matemática. Pedagogia Freinet.

\begin{abstract}
This research describes the learning paths of children in Early Childhood Education in their experimental groping involving mathematical knowledge. In this sense, the objective of this study is to answer the following research problem: "What experiences can be planned, considering the participation of children, aiming at learning mathematical concepts within the assumptions of Freinet Pedagogy?". For the studies, the theoretical references of Pedagogy Freinet were used, such as Freinet (1996), Sampaio (2006) and Mathematical Education, such as Lorenzato (2008) and Smole (2003). The research methodology used was action research. The results indicate that planned interventions were able to create expanded contexts for learning mathematics resulting in learning that was present in games and interactions between children during class routines such as skipping-rope, playing hopscotch, mathematical games, use of room maps and counting records.

Keywords: Childhood Education. Mathematics Education. Freinet Pedagogy.
\end{abstract}




\section{INTRODUÇÃO}

Ao longo do tempo, vários documentos oficiais foram elaborados a fim de tornar a Educação Infantil um espaço de aprendizagem como direito da criança. As Diretrizes Curriculares Nacionais para a Educação Infantil (DCNEI) trazem várias contribuições nesse sentido, ressaltando inclusive que as experiências pedagógicas na Educação Infantil devem garantir experiências que recriem "em contextos significativos para as crianças, relações quantitativas, medidas, formas e orientações espaço temporais” (BRASIL, 2010, p. 25).

Na mesma perspectiva, a BNCC - Base Nacional Comum Curricular (Brasil, 2017) coloca as experiências das crianças na Educação Infantil como elemento chave para aprendizagem quando destaca que:

\section{as creches e pré-escolas têm o objetivo de ampliar o universo de experiências, conhecimentos e habilidades dessas crianças, diversificando e consolidando novas aprendizagens, atuando de maneira complementar à educação familiar (BRASIL, 2017, p. 34).}

O cotidiano da Educação Infantil ganha destaque nesse tipo de concepção visto que "a interação durante o brincar caracteriza o cotidiano da infância, trazendo consigo muitas aprendizagens e potenciais para o desenvolvimento integral das crianças" (BRASIL, 2017, p. $35)$.

A matemática é um campo de saberes que se faz presente em diversas situações cotidianas de adultos e crianças. No contexto da Educação Infantil, a partir da percepção de que estamos imersos em contextos nos quais a matemática é necessária para a vida, encontram-se possibilidades para proporcionar situações de aprendizagem na Educação Infantil.

Aliado a esta ideia de aprendizagem por meio de contextos da vida, se encontra a proposta pedagógica embasada pelas obras de Célestin Freinet. Este educador nos convida a refletir sobre o nosso papel enquanto professores, assim como diz Freinet (1996):

\footnotetext{
[...] Arregace as mangas para trabalhar com as crianças. Deixe de dar ordens e castigar, atire-se ao trabalho com os alunos. Não tenha medo de sujar as mãos, de se machucar com uma martelada, de hesitar nos casos em que a criança mais viva domina a situação, de tatear, de se enganar, de recomeçar. Assim é a vida, e é o esforço que fazemos lealmente, para dominar seus incidentes, que constitui o principal elemento da nossa educação (FREINET, 1996, p. 92).
}

Freinet defendeu uma pedagogia para a vida, na qual a criança é protagonista de suas aprendizagens e era contra a ideia do ensino isolado de contextos da vida da criança. Ele foi idealizador de uma série de técnicas dentro das suas concepções de aprendizagem que privilegiam os fazeres próprios das crianças em sua vida. 
Uma vez que se reconhece que a matemática, assim como outros saberes, não se encontra em contextos isolados do mundo mas atrelada aos fazeres da vida humana, surge o desafio de planejar vivências em que as crianças consigam experienciar a matemática de maneira significativa, contextualizada e respeitando os contextos das infâncias das crianças (TORTORA, 2019).

Pensando nesse desafio, dentre outros tantos que envolvem os fazeres do papel do professor de Educação Infantil, um grupo de professores (dentre eles, o pesquisador) e a equipe gestora de uma instituição de Educação Infantil de Campinas dedicaram-se, durante o ano de 2019, a estudar e pesquisar os próprios contextos e estabelecer ações para solucionar seus problemas frente aos desafios que a Educação Infantil propõe.

Dentre os vários assuntos abordados nas reuniões de estudos e planejamentos, encontrou-se o desafio de proporcionar novas formas de aprender matemática na Educação Infantil. Considerando que o Projeto Pedagógico da instituição direcionava as práticas docentes para técnicas da Pedagogia Freinet, este texto é fruto de investigações das possibilidades de aprendizagem de matemática dentro dos pressupostos da Pedagogia Freinet com as crianças da Educação Infantil.

A fim de garantir, inclusive, o caráter científico junto aos estudos e pesquisas realizados, os processos de formação, ação e reflexão sobre as práticas foram modelados dentro de pressupostos metodológicos da pesquisa-ação em um viés qualitativo.

No texto deste artigo, encontram-se alguns apontamentos sobre a Pedagogia Freinet e suas possíveis relações com a aprendizagem de matemática na Educação Infantil, apontamentos sobre os pressupostos que configuram esta pesquisa dentro de uma prática de pesquisa-ação e a apresentação de alguns dos percursos trilhados pelas crianças da Educação Infantil na aprendizagem de conceitos matemáticos e que puderam ser observados pelo professor.

\section{Apontamentos sobre a Pedagogia freinet e possíveis relações com a APRENDIZAGEM DE MATEMÁTICA NA EDUCAÇÃo INFANTIL}

A Pedagogia Freinet está embasada nos pressupostos teóricos de Célestin Freinet, um educador francês que desenvolveu uma obra que serve de referência para muitas propostas pedagógicas em diferentes níveis de ensino.

Freinet é reconhecido por uma postura humanista e por ser militante do cooperativismo. Dentro de seus ideais, ele acredita que a escola deveria ter uma íntima relação com a vida. 
Influenciado por várias ideias de Marx e Engels, Freinet desenvolveu uma pedagogia socialista, que articula as relações entre escola, trabalho e sociedade.

Freinet idealizava uma escola que fosse centrada na criança e estimulasse protagonismo dos pequenos em suas aprendizagens de maneira articulada com a vida. $\mathrm{O}$ professor teria o papel de intermediar e ajudar a construção de seus conhecimentos com significado para a vida das crianças.

Nesse sentido, os pressupostos de Freinet se contrapõe a ideia de disciplinas aprendidas fora de contexto e que valorizassem apenas a memorização. Ele propõe um trabalho em que parta da vontade dos estudantes e que seja articulado com um ambiente educacional com diversidade de materiais e técnicas de trabalho que resultem em aprendizagens coletivas e individuais. Nas palavras de Freinet (1996):

[...] não podemos, atualmente, pretender conduzir metódica e cientificamente as crianças; ministrando a cada uma delas a educação que lhe convém, iremos nos contentar com preparar e oferecer-lhes ambiente, material e técnica capazes de contribuir para sua formação, de preparar os caminhos que trilharão segundo suas aptidões, seus gostos e suas necessidades (FREINET, 1996, p. 10).

Dentre suas várias propostas, Freinet salienta o tateamento experimental. Sampaio (2006) explica que o tateamento é:

a aptidão para manipular, observar, relacionar, emitir hipóteses, verificá-las, aplicar leis e códigos, compreender informações cada vez mais complexas. É uma atitude particular que deve ser desenvolvida pouco a pouco, assim os conhecimentos vão sendo adquiridos pela criança e se enraízam profundamente nela, permanecendo, entretanto, revisáveis e relativos, quando aparecem novos fatos ou quando são feitas novas experiências. O tateamento é, ao mesmo tempo, o processo de busca pela aprendizagem e a aprendizagem propriamente dita através da experimentação (SAMPAIO, 2006, p. 217).

Por meio desse princípio, é possível perceber a relação próxima entre as experimentações da criança e suas aprendizagens. A criança tem a liberdade de trilhar os caminhos para sua aprendizagem dentro do seu ritmo, sendo que o professor tem a fundamental importância de organizar situações, planejar tempos e espaços, escolher materiais, entre outras ações que visem boas situações para o tateamento experimental das crianças.

Essa concepção demanda uma configuração de práticas na Educação Infantil que exige a organização de espaços e tempos voltados para aprendizagens das crianças possibilitando o tateamento experimental das crianças.

Existem várias práticas e técnicas propostas pela Pedagogia Freinet que valorizam o tateamento experimental das crianças e dentre elas encontram-se os ateliês de trabalho. Gomes (2015) descreve os ateliês de trabalho da seguinte forma: 
Os ateliês de trabalho estão relacionados a atividades diversificadas e simultâneas, que podem ser desenvolvidas individualmente e/ou em pequenos grupos. Cada ateliê comporta um determinado número de crianças de maneira que possam trabalhar tranquilamente, se inscrevem levando em consideração a quantidade de crianças que o ateliê comporta. O tempo que ficará em determinado ateliê está diretamente ligado à necessidade e interesse da criança sem deixar de lado a responsabilidade, o comprometimento pela escolha e trabalho desenvolvido. As crianças têm liberdade de ação passam de um ateliê para o outro, é livre para escolher, mas é uma liberdade situada não pode escolher não fazer nada (GOMES, 2015, p. 112).

Nesse sentido, além das brincadeiras e planejamento de discussões cotidianas com as crianças, os ateliês de trabalho foram recursos bastante úteis para estimular as aprendizagens das crianças. Dentre os ateliês organizados em espaços da sala das crianças, está o ateliê da matemática, o qual concentra uma série de materiais que estimulam o tateamento experimental com números, elementos de geometria, medidas, etc.

Sobre a aprendizagem de matemática por crianças da Educação Infantil, Tortora (2019) descreve que as brincadeiras e interações se tornam um terreno fértil para as aprendizagens matemáticas das crianças da Educação Infantil. Segundo o autor, "a criança está imersa em um mundo de conhecimentos matemáticos desde o nascimento e acaba interagindo com eles cotidianamente o que gera uma experiência pessoal com a matemática".

Nesse sentido, faz-se necessário planejar práticas que visem a aprendizagem de matemática associadas às situações da vida da criança, a qual já traz consigo uma bagagem de vivências com a matemática que podem fazer parte das suas aprendizagens. Lorenzato (2008), ressalta que:

essa bagagem, que difere de criança para criança, precisa ser identificada pelo professor e, se possível, com o auxílio dos pais; o respeito a essa experiência pessoal é fator determinante para que sejam atingidos os objetivos desejados (LORENZATO, 2008, p. 24).

Smole (2003), salienta que algumas práticas vão na contramão desse pensamento:

Comumente os professores se preocupam em transmitir às crianças da escola infantil rudimentos de noções numéricas - reconhecimento de algarismos, nomes dos números, domínio da sequência numérica - e os nomes de algumas figuras geométricas. Por trás desse trabalho está a concepção de que o conhecimento matemático vai ocorrer fundamentalmente através de explicações claras e precisas que o professor fizer. (SMOLE, 2003, p. 62)

Ao nos referirmos ao papel da Educação Infantil frente as situações de aprendizagem de matemática, encontramos na Pedagogia Freinet pressupostos e técnicas que possibilitam o desenvolvimento de conceitos matemáticos de forma significativa para as crianças. Dentro deste pressuposto, o professor não planeja uma "aula de matemática" para crianças da Educação Infantil. Na contramão desta ideia, o docente planeja e provoca situações, convida para reflexão, 
cria contextos, questiona as crianças e valoriza as hipóteses dos pequenos em situações que eles tenham experiências com matemática e outros tantos saberes.

Tais concepções moveram os estudos feitos em reuniões com professores e mobilizaram a realização desta pesquisa. A seguir estão descritas algumas características da pesquisa-ação, a qual foi desenvolvida dentro da instituição em que o pesquisador trabalha com contribuições de outras professoras.

\section{ASPECTOS METODOLÓGICOS}

O objetivo deste estudo foi responder ao problema de pesquisa que motivou o professor e as professoras a aprofundar suas investigações na temática aqui apresentada: "Quais vivências podem ser planejadas, considerando a participação das crianças, a fim resultarem na aprendizagem de conceitos matemáticos dentro de pressupostos da Pedagogia Freinet?”.

Esta pesquisa teve caráter qualitativo, a qual não tem a intenção de ser generalista, mas pretende descrever possibilidades de trabalho com crianças da Educação Infantil a partir de contextos semelhantes ao deste estudo. Garnica (2004) apresenta algumas características da pesquisa qualitativa e que foram consideradas neste estudo:

Segundo minha concepção, o adjetivo "qualitativa" estará adequado às pesquisas que reconhecem: (a) a transitoriedade de seus resultados; (b) a impossibilidade de uma hipótese a priori, cujo objetivo da pesquisa será comprovar ou refutar; (c) a não neutralidade do pesquisador que, no processo interpretativo, se vale de suas perspectivas e filtros vivenciais prévios dos quais não consegue se desvencilhar (GARNICA, 2004, p. 88).

Além da transitoriedade e da não apresentação de hipóteses a priori, destaca-se nesse estudo a não neutralidade do pesquisador no processo de interpretação e análise dos resultados, visto que o pesquisar é o professor das crianças que participaram desse estudo.

Garnica (2004, p.88) afirma que a pesquisa qualitativa também tem por característica que a "constituição de suas compreensões dá-se não como resultado, mas numa trajetória em que essas mesmas compreensões e também os meios de obtê-las podem ser (re)configurados".

Nesse sentido, os caminhos trilhados na condução das práticas com as crianças descritos nesse estudo não devem ser meramente copiados a fim de chegar aos mesmos resultados em outras instituições, mas devem servir como meio para suscitar reflexões sobre a aprendizagem de conhecimentos matemáticos na Educação Infantil sejam (re)significadas.

Nesse sentido, Günther (2006) explica que a pesquisa qualitativa tem algumas características que podem auxiliar outros professores a alcançar os mesmos resultados com seus estudantes: 
são características da pesquisa qualitativa sua grande flexibilidade e adaptabilidade. Ao invés de utilizar instrumentos e procedimentos padronizados, a pesquisa qualitativa considera cada problema objeto de uma pesquisa específica para a qual são necessários instrumentos e procedimentos específicos (GÜNTHER, 2006, p. 204).

Tendo como finalidade contribuir com as práticas de outros docentes que tenham as mesmas preocupações deste pesquisador, essa investigação fez uso da metodologia de pesquisaação, a qual se enquadra dentre os métodos de investigação-ação. Coutinho et al. (2009) aponta que esta metodologia é essencialmente prática, bem como é regida pela necessidade de resolver um problema do contexto do pesquisador. Basicamente, o pesquisador toma ciência de um problema a ser investigado e anuncia ações para poder resolver o problema. Segundo os autores:

\footnotetext{
Sabendo que a metodologia de Investigação-Ação alimenta uma relação simbiótica com a educação, que é a que mais se aproxima do meio educativo sendo mesmo apresentada como a metodologia do professor como investigador e que valoriza, sobretudo, a prática, tornando-a, talvez, o seu elemento chave. (COUTINHO et al 2009, p.358)
}

A investigação-ação está ligada intimamente com a prática que o professor exerce e sempre vem acompanhada de reflexões sobre os contextos do professor e seus objetivos com sua prática. Coutinho et al. (2009) salientam que existe uma preocupação que visa a transformação da realidade e, por conseguinte, se produz conhecimento sobre as transformações resultantes da ação.

Sobre a pesquisa-ação, Dionne (2007) salienta que existem muitas definições deste método de estudos, entretanto, ele indica que existe um aspecto comum entre elas: "a importância do vínculo que une os pesquisadores e os atores ou profissionais" (p. 44). Além disso, ele sugere que se conceitue pesquisa-ação da seguinte forma: “[...] prática que associa pesquisadores e atores em uma mesma estratégia de ação para modificar uma dada situação e uma estratégia de pesquisa para adquirir um conhecimento sistemático sobre a situação identificada" (p. 68).

Como Dione (2007) descreve, esse tipo de estratégia de pesquisa permite mobilizar recursos pedagógicos a fim de modificar uma dada situação. Franco (2005) amplia esse posicionamento e aponta que a pesquisa-ação possibilita um mergulho crítico na práxis do professor e, por conseguinte, buscar (re)significar suas práticas .

Sobre o planejamento de uma pesquisa-ação, Thiollent (1996) descreve que existe uma flexibilidade quanto as fases de realização da pesquisa-ação e sugere algumas temáticas a serem utilizadas ao longo do trabalho de investigação. Tendo em conta essa flexibilidade, estão descritas a seguir as fases pelas quais este estudo passou: 
a.) A "fase exploratória", a qual teve por objetivo conhecer os campos de pesquisa, os interessados e suas expectativas. No caso, temos o professor interessado em promover a aprendizagens de matemática pelas crianças em contextos do projeto pedagógico da instituição de Educação Infantil em que trabalha.

b.) A "escolha do tema" da pesquisa, que ficou definida como sendo a organização de situações de aprendizagem de matemática pelas crianças da Educação Infantil de acordo com pressupostos da Pedagogia Freinet.

c.) A "colocação dos problemas", na qual se define o referencial teórico a ser utilizado, ficou estabelecido que o problema a ser investigado seria "Quais vivências podem ser planejadas, considerando a participação das crianças, a fim resultarem na aprendizagem de conceitos matemáticos dentro de pressupostos da Pedagogia Freinet?".

d.) A "construção do plano de ação", o qual nesse caso ficou delimitado pelo professor e descrito em seu planejamento anual no trabalho com as crianças. A seguir, estão descritas as ações planejadas pelo professor para as intervenções nos tempos e espaços de aprendizagem das crianças:

a. Vivências diárias com a escrita numérica por meio da contagem das crianças e registro dos presentes.

b. Planejamento do "ateliê da matemática", no qual as crianças são estimuladas a aprender matemática com jogos e outros recursos desenvolvidos pelo professor ou comprados com recursos financeiros da unidade educacional.

c. Brincadeiras semanais, por escolha das crianças, que envolvam habilidades de correspondência, comparação, classificação, ordenação, inclusão e conservação, as quais são processos mentais que são básicos para a aprendizagem da matemática (LORENZATO, 2008).

d. Exploração das manifestações das crianças que incentivem a criação de situações de aprendizagem de matemática.

e.) O "estudo da relação entre saber formal e saber informal", diz respeito ao estudo feito pelo professor a fim de estabelecer maneiras de comunicação entre a intencionalidade pedagógica do professor e os interesses das crianças.

f.) Por fim, existe a "divulgação externa", a qual se dá por meio da publicação dos resultados desta pesquisa e pela avaliação das crianças divulgada às famílias.

Em complemento, Thiollent (1996) descreve que há a "delimitação de observação, amostragem e representatividade qualitativa", a "coleta de dados" descritas no decorrer deste artigo. Para esta pesquisa, inicialmente, foi feita uma análise dos conhecimentos das crianças a 
respeito dos números, geometria e medidas, em seguida foram feitos estudos sobre a Pedagogia Freinet e sua presença na Educação Infantil em formações e discussões nos momentos de reuniões de professores, as quais aconteceram na própria unidade educacional.

Seguindo os princípios da pesquisa qualitativa, os dados foram analisados de forma descritiva e interpretativa, considerando que esta pesquisa-ação possa "gerar reações e contribuir para a dinâmica da tomada de consciência e, eventualmente, sugerir o início de mais um ciclo de ação e de investigação" (THIOLLENT, 1986, p. 71).

Para registrar o progresso de aprendizagem das crianças foi utilizado um diário de campo do professor, no qual constam anotações frente aos avanços das crianças e um portfólio construído pelo professor com produções das crianças frente às aprendizagens conquistadas no decorrer do ano letivo.

A coleta de dados ocorreu durante todo ano letivo de 2019 em um Centro de Educação Infantil de um município do interior paulista. Neste texto, estão descritos os percursos de aprendizagem de três crianças que fizeram parte do agrupamento no qual o pesquisador era o professor da turma.

\subsection{OS ENCONTROS FORMATIVOS ENTRE OS PROFESSORES}

A ideia inicial das formações ocorreu por conta de uma renovação no quadro de professores do Centro de Educação Infantil (CEI) em que a pesquisa ocorreu. O pesquisador foi um dos membros que compôs o novo quadro docente e, assim como os demais, estava em processo de adaptação ao novo ambiente de trabalho. Este CEI tem um projeto pedagógico embasado em práticas da Pedagogia Freinet, no qual os antigos professores já estavam habituados, porém os novos professores se viram desafiados a se adaptar à nova proposta pedagógica.

A equipe gestora do CEI, preocupada com os novos docentes, planejou (em conjunto com os novos professores) momentos de estudo e reflexão sobre a nova rotina de trabalho com as crianças. Durante esses encontros, diversas problemáticas foram sendo elencadas pelos docentes e discutidas entre os professores em momentos semanais de Trabalho Docente Coletivo (TDC). Essas problemáticas foram elencadas e logo surgiu a ideia da instituição de educação infantil organizar momentos de formação com parceiros externos a fim de solucionálas.

As formações externas ocorreram em forma de exposição dialogada em três encontros, os quais tiveram as seguintes problemáticas: “A Pedagogia Freinet e as práticas na Educação 
Infantil", "A organização da sala em forma de ateliês de trabalho" e "Diálogos entre Matemática e a Pedagogia Freinet na Educação Infantil". Vale ressaltar que as pessoas que ministraram as formações são antigas professoras do Centro de Educação Infantil (já aposentadas).

Essas formações serviram para discutir e elencar coletivamente vários problemas a serem investigados frente aos novos desafios de se trabalhar com uma pedagogia até então desconhecida, bem como lidar com questões consideradas desafiadoras pelos docentes como o trabalhado com matemática na Educação Infantil.

\subsection{DESCRIÇÃO DAS CRIANÇAS PARTICIPANTES}

Para ilustrar os resultados das intervenções e estudos planejados durante as reuniões de professores, os docentes do grupo organizaram momentos de troca de experiências. Durante esses encontros foram compartilhadas as produções de três crianças, as quais mostravam avanços da aprendizagem de matemática e que, de acordo com os professores, poderiam ilustrar possíveis percursos de aprendizagem resultados dos planejamentos do professor, os quais são frutos dos estudos feitos pelo grupo de professores.

Tomando os devidos cuidados éticos, as três crianças foram convidadas a participar dos relatos presentes neste artigo. Os responsáveis pelas crianças foram chamados para uma reunião e informados sobre os objetivos e conteúdo da pesquisa aqui relatada. Além disso, assinaram um "Termo de Livre Consentimento e Esclarecimento", no qual concordaram com a divulgação dos protocolos aqui apresentados mantendo o anonimato das crianças. Por esse motivo, neste texto as crianças receberam os nomes fictícios de Paulo, Isadora e João.

Para além das autorizações dos responsáveis, respeitando as ideias e autorias dos pequenos, as três crianças também foram consultadas para que permitissem a divulgação os seus trabalhos para o público externo, as quais concordaram com a decisão.

Paulo era um menino de quatro anos de idade que gosta muito de brincadeiras que envolvam movimento. Ele gostava de jogar futebol, brincar de pega-pega e pular corda. Na sala, ele se sentia mais à vontade em atividades que envolviam jogos, carrinhos e atividades de desenho. Ele mostrava-se bastante participativo e extrovertido, além de gostar de ajudar os colegas nos afazeres da sala, como organizar os brinquedos ou apagar a lousa. Com relação à matemática, Paulo apresentava dificuldades ao contar objetos, escrever e ler números e reconhecer figuras geométricas.

Isadora era uma menina de cinco anos de idade que estava sempre acompanhada das suas amigas no dia a dia. Durante as rotinas da turma, ela sentia-se mais à vontade em atividades 
que envolviam suas amigas. Ela prezava muito pela organização dos brinquedos da sala e de seus pertences, sempre os guardando de forma bastante estratégica. Por exemplo, como ela mesmo definiu, as bonecas deveriam ficar em caixas separadas dos carrinhos, além de estarem organizadas da menor para a maior dentro das caixas. Percebe-se que ela conseguia fazer uso dos processos mentais para aprendizagem de matemática descritos por Lorenzato (2008) de forma bastante natural para organizar sua rotina de brincadeiras. Porém, Isadora tinha as mesmas dificuldades que Paulo ao contar objetos, escrever e ler números e reconhecer figuras geométricas.

João apresenta um perfil distinto das outras duas crianças. Ele era uma criança que já estava alfabetizada aos quatro anos de idade, o que afetava sua aprendizagem de matemática. Ao contrário do restante da turma, ele apresentava conhecimentos que iam além do esperado para crianças da sua idade, como já saber contar até números maiores que cem, reconhecer ordem crescente e decrescente dos números, reconhecer um grande número de figuras geométricas, realizar algumas somas com números de dois dígitos etc. Para o João, o desafio seria provocar situações de aprendizagem de matemática com conhecimentos mais avançados dos esperados para a Educação Infantil.

\subsection{AS ESTRATÉGIAS UTILIZADAS PARA APRENDIZAGEM DE MATEMÁTICA DAS CRIANÇAS}

Após o reconhecimento das dificuldades e desafios apresentados pelas crianças, buscouse conhecer possibilidades de interação com conhecimento matemático, respeitando as escolhas das crianças e suas vontades.

A princípio, destaca-se o protagonismo das crianças nas situações de contagem. Talvez, essa seja uma das práticas mais famosas entre os educadores, os quais acabam contando "meninos e meninas", "presentes e ausentes", etc. Porém, buscando dar significado a essa prática, as crianças faziam a contagem diária com o intuído de informar à cozinha a quantidade de crianças presentes para o preparo da refeição a ser realizada no dia.

Estar aberto "a todas as possibilidades que, por não serem conhecidas de antemão, surgem no percurso de nossa relação com as próprias crianças e com os espaços e tempos educativos" (CAMPINAS, p. 24) é um recurso potencial para aprendizagens das crianças. Sendo assim, algumas manifestações espontâneas serviram como recursos para proporcionar situações pedagógicas.

O espaço físico da sala tem relevante importância na aprendizagem das crianças, nesse sentido, destaca-se o "Ateliê da Matemática". Nesse espaço, estão dispostos uma série de 
materiais para exploração das crianças, os quais sugerem experiências com números, medidas, geometria etc. Compõe esse espaço os jogos de percurso, jogos de tabuleiro, jogos de cartas, jogo da memória, tangram, balanças, fitas métricas, alguns jogos de construção e os numerais de parede (construídos com as crianças). As crianças tinham autonomia no manuseio dos materiais e eram responsáveis pela sua utilização e organização.

Outras práticas escolhidas para incentivar a aprendizagem de matemática foram brincadeiras estimuladas pelo professor ou trazidas pelas crianças e que envolviam saberes relacionados às quantidades, relações com o espaço e contagem para a brincadeira. Não houve a intenção de "didatizar" as brincadeiras das crianças, mas de ampliar as possibilidades de aprendizagem pela brincadeira. As brincadeiras selecionadas pelo professor e sugeridas pelas crianças foram: amarelinha, pular corda, brincar de elástico, brincadeiras de roda cantadas e a "amarelinha africana". Cada uma tem regras bem definidas, porém foram discutidas em grupo com as crianças e desenvolvidas no parque, no pátio ou em sala.

\section{Percursos e aPRendizagens das CRIANÇAS nOS SEUS FAZERES COM A MATEMÁtiCA: RESULTADOS DAS PRÁTICAS ESTUDADAS E VIVIDAS.}

Nesta seção estão descritos os avanços das crianças na aquisição de conhecimentos matemáticos que foram percebidos ao longo do ano letivo. A problemática que moveu as discussões deste estudo centrou-se na preocupação com as aprendizagens de matemática pelas crianças que ressaltassem o seu protagonismo e não se apoiasse em práticas mecânicas e sem significado.

Os resultados aqui apresentados não têm a intensão de mostrar um cenário de "antes e depois" das práticas, uma vez que nos propomos a acompanhar as aprendizagens das crianças não de maneira linear, mas com idas e vindas que se dão dentro da complexidade do ato de ensinar e aprender com crianças. Sendo assim, estão descritos a seguir alguns percursos de aprendizagem das crianças durante o seu tateamaneto experimental (SAMPAIO, 2006), os quais foram vivenciados por consequência da ação intencional dos planejamentos propostos alinhados às discussões feitas nas reuniões de professores.

Paulo, a primeira criança aqui apresentada, iniciou o ano letivo com pouco interesse sobre as atividades propostas, nesse sentido o professor percebeu necessidade de buscar ações que fossem mais atrativas para que ele aprendesse junto das outras crianças. Após estudos sobre a teoria que embasa a prática do professor e observando as formas como a criança aprende, 
buscou-se algumas brincadeiras que contemplassem os objetivos do professor para as aprendizagens do Paulo.

No parque, Paulo e outras crianças foram convidadas a brincar de corda. Segundo Smole, Diniz e Cândido (2000, p.54), "mais que exercitar o corpo e se relacionar com o grupo, a brincadeira com corda leva a criança a compreender sua ação e a desenvolver o pensamento lógico-matemático através de relações espaço-temporais".

Paulo ficou muito interessado pela brincadeira. Recorrendo aos conhecimentos adquiridos nos percursos formativos, o professor tornou a brincadeira mais desafiante e sugeriu a Paulo que contasse quantas vezes ele conseguia pular a corda sem errar. Ele sempre tentou se superar ao longo das tardes no parque e, ao término da rotina, para lembrar-se da quantidade de pulos que ele conseguiu pular, ele fez uma marcação no chão do parque com ajuda do professor. Ele se interessou pela escrita numérica por meio desta brincadeira e gostava de compartilhar com os amigos esses seus registros, como a Figura 1 ilustra, ele registrou na lousa que havia conseguido pular a corda 16 vezes para lembrar de contar aos colegas.

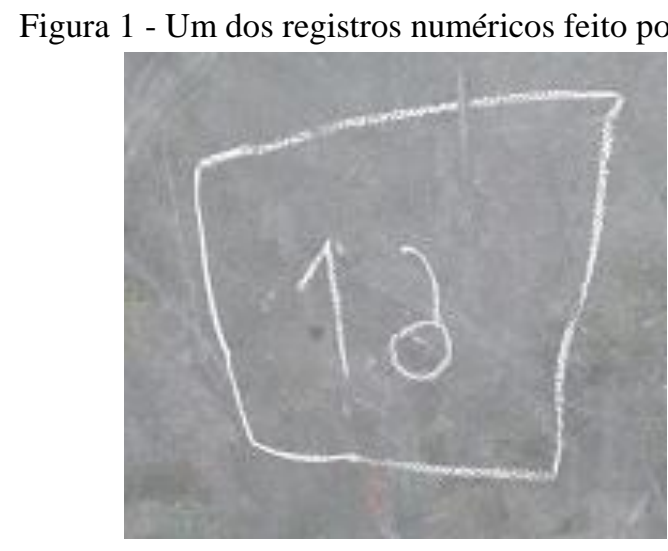

Fonte: Arquivos do autor.

Além do registro de números, Paulo exercitava a contagem enquanto pulava, além de desenvolver aspectos motores e sociais vinculados a própria brincadeira. Logo, a brincadeira de pular corda foi um recurso bastante válido para as aprendizagens de Paulo e fruto das discussões em estudos feitos com outros professores.

Com o tempo, Paulo passou a levar essas aprendizagens para outros espaços, como aconteceu no ateliê da matemática. O tateamento experimental dos materiais que ali se encontravam possibilitou uma série de experiências que resultaram em saberes significativos para as crianças (SAMPAIO, 2006).

Nesse ateliê, se encontravam pequenos pedaços de madeira com os quais as crianças brincavam de fazer algumas construções. Em um dia de brincadeiras na sala, Paulo chamou o 
professor para mostrar que estava tentando "escrever" os números utilizando as madeiras e que havia conseguido fazer o número oito, conforme a foto a seguir:

Figura 2 - Construção de números feita por Paulo em sua exploração dos materiais do ateliê da matemática

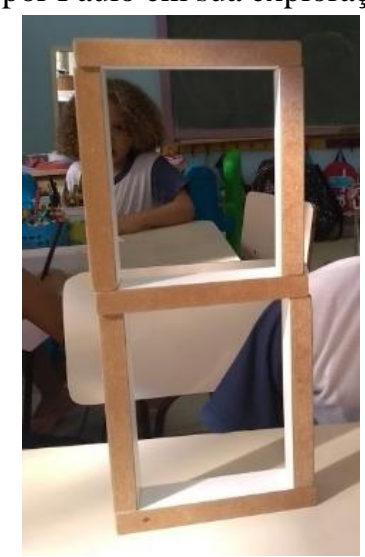

Fonte: arquivos do autor.

Com o tempo, Paulo passou a ficar mais interessado pelo ateliê da matemática. O professor, percebendo que ele estava com dificuldades em reconhecer alguns numerais elaborou o "jogo na mãozinha" (batizado desta forma pelas crianças).

Nesse jogo, cada jogador recebe o mesmo número de cartas viradas para baixo (cartas numeradas de 0 a 10). As crianças e vão jogando as cartas sobre a mesa (seguindo o sentido escolhido pelo grupo) e tentando adivinhar o número que estava escondido na carta a ser virada. Caso a criança adivinhe a carta, ela pode ficar com as cartas que estão sobre a mesa. Ganha o jogo quem estiver com todas as cartas.

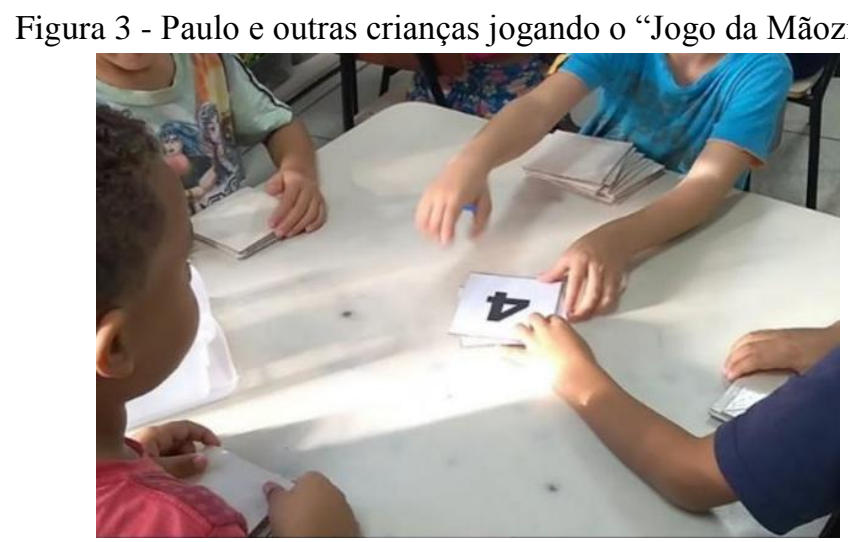

Fonte: arquivos do autor.

Paulo gostou muito de brincar com esse jogo, mas estava com dificuldades em reconhecer os números. Percebendo essa dificuldade, o professor conversou com João sobre o jogo e estimulou que ensinasse Paulo a jogar esse jogo. João aceitou a condição e logo se interessou bastante por esse jogo. Assim como outras crianças, o jogo mobilizou tateamentos 
experimentais diferentes para as duas crianças: para além do aspecto da matemática, estimulouse o espirito de colaboração entre as crianças.

Pelas características do João, o "Jogo da Mãozinha" não traria grandes novidades para ele quanto a aprendizagem de matemática. Após as formações e discussões com colegas nos momentos de formação e observando as preferências de João, o professor percebeu que o ateliê da informática seria um espaço com boas possibilidades de aprendizagem para João. Sendo assim, foram selecionados uma série de softwares que trariam novas possibilidades de tateamento experimental neste espaço. Dentre os softwares, destaca-se nesse texto um jogo para aprender múltiplos, no qual ele deveria selecionar múltiplos (de dois até nove) num jogo estilo "pac-man".

Figura 4 - O jogo de “caça aos múltiplos” sendo jogado no ateliê da informática

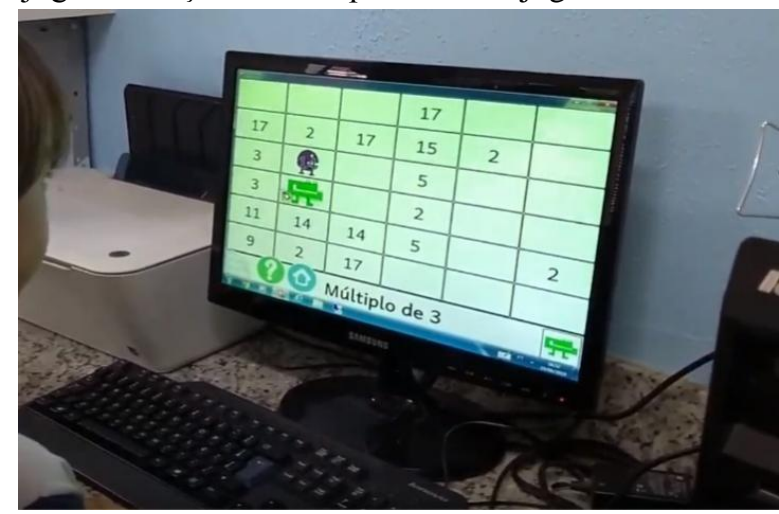

Fonte: arquivos do autor

João se interessou muito pelo jogo e pelo desafio de aprender a como saber quais eram os múltiplos pedidos pelo jogo. Ele conseguiu aprender formas de descobrir os múltiplos dos números e memorizá-los. Com o tempo, o jogo foi caindo no gosto das outras crianças e João convidava seus amigos para brincar com ele.

As outras crianças não conseguiam saber o conceito de "múltiplo", porém desenvolveram uma forma de jogar juntos: enquanto João falava quais são os múltiplos pedidos pelo jogo, as crianças buscavam por eles na tela, o que provocava uma situação de leitura numérica, na qual as crianças poderiam desenvolver essa habilidade com a ajuda de João.

Para ajudar seus amigos na leitura desses números, em uma manifestação espontânea, João decidiu compartilhar com a turma uma "tabela de números" (nomeada assim por João) que ele havia escrito em casa e trouxe para compartilhar com os colegas. Por meio dessa tabela ele quis compartilhar uma maneira de reconhecer múltiplos. Foi um momento bastante rico em aprendizagens tanto para João como para os colegas. 
Figura 5 - Números escritos por João para compartilhar com a turma

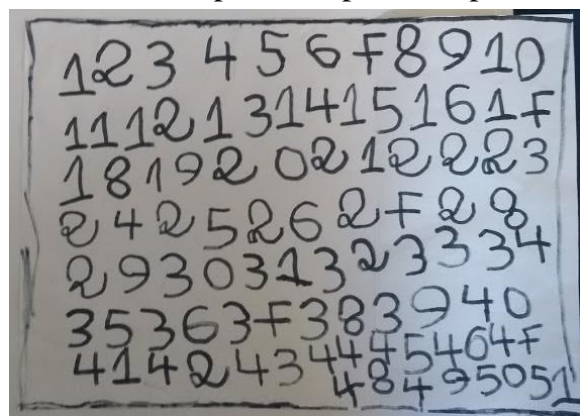

Fonte: arquivos do autor

Naquele dia, as crianças exploraram as anotações de João e puderam perceber regularidades nas escritas numéricas. As crianças tiveram várias experiências com a escrita numérica e o João pode contribuir com os saberes dos colegas no ateliê da lousa.

Figura 6 - As crianças escrevendo números na lousa por influência dos registros de João

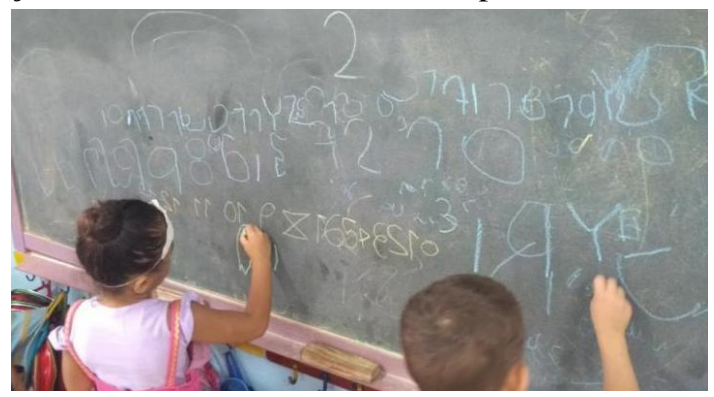

Fonte: arquivos do autor

Dentre as crianças que se interessaram por essa prática, se encontra Isadora. Ela não havia se interessado muito pelos registros numéricos até então, mas começou a perceber que eles poderiam ter utilidade no seu dia a dia. Ela é uma criança que gosta muito de ajudar o professor e, logo que o professor percebeu isso, transformou a prática de contar crianças em momentos de aprendizagem para Isadora visto que seria ela a auxiliar o professor no registro das contagens.

Todos os dias, as crianças faziam a contagem dos presentes com o intuito de informar esse número às cozinheiras, uma vez que ele seria usado para estipular a quantidade de refeições a serem feitas naquele dia. Após a contagem, a Isadora se responsabilizou pelo registro numérico da quantidade de crianças presentes na sala, o qual se fazia importante porque uma funcionária da escola viria a nossa sala para coletar aquela informação.

Considerando essa necessidade, Isadora passou a se preocupar pela forma padrão da escrita numérica, visto que ela seria consultada por outra pessoa. Nesses momentos de escrita, Isadora aprendeu a escrever vários números diferentes e, quando não sabia como representálos, buscava ajuda do professor ou dos seus colegas para fazer as anotações. 
Isadora também gostava muito de ajudar os colegas da turma, inclusive os que eram novos na sala. Ela gostava muito de mostrar a sala aos colegas apresentando e mostrando onde cada ateliê estava localizado. Percebendo essa característica, o professor elaborou um mapa da sala, o qual se assemelha a planta baixa e serviria para representar graficamente a localização dos espaços de aprendizagem.

O mapa foi levado para a sala para que as crianças fizessem a sua leitura e apresentassem aos colegas a forma como combinamos de organizar os espaços da sala.

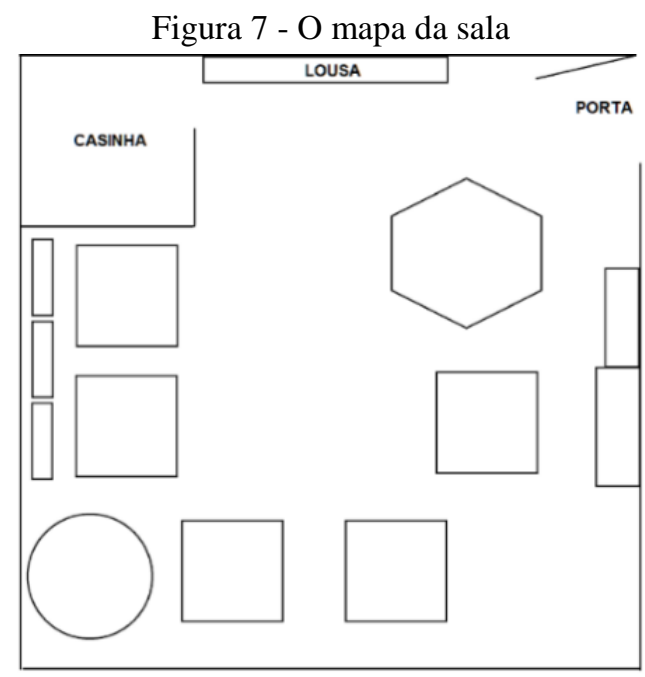

Fonte: arquivos do autor

Ao longo do ano, as crianças foram identificando os espaços do mapa e usando-o para organizar atividades pela sala. Isadora foi uma das crianças que mais fez uso do mapa, o que era percebido quando gostava de compartilhar formas de brincar na sala e reorganizar o espaço. Como exemplo, num dado momento a turma gostaria de brincar de dança das cadeiras e Isadora mostrava no mapa formas de organizar as mesas a fim de termos mais espaço para a brincadeira.

Além das atividades com o mapa, Isadora despontava aprendizagens na sua participação no ateliê da matemática. Assim como aponta Gomes (2015), nos ateliês a criança pode escolher suas atividades.

No ateliê da matemática, Isadora fazia construções de mosaicos combinando quadrados, paralelogramos, triângulos, etc. Os quais eram compartilhados com a turma. O professor fazia alguns desafios para Isadora, como "fazer uma construção com seis triângulos, quatro quadrados e dos paralelogramos”, os quais motivavam Isadora na brincadeira e suscitavam aprendizagens geométrica.

Isadora também gostava muito de contribuir com os materiais dos ateliês. Por exemplo, certa vez ela se propôs a construir um jogo da memória que viria a fazer parte do acervo de 
jogos do ateliê da matemática. Por sugestão do professor, ela fez um jogo da memória representando quantidades nas peças do jogo de sua autoria.

Aqui foram selecionados apenas alguns exemplos frente aos registros feitos pelo professor das práticas desenvolvidas com as crianças, porém outros tantos não menos importantes fizeram parte dos contextos de aprendizagem das crianças. Essas e outras situações servem para ilustrar o potencial criativo das crianças que foi estimulado pela organização dos tempos e espaços de aprendizagem num contexto colaborativo de estudos e planejamento.

\section{CONSIDERAÇões FinaIS}

Quando um professor se apresenta em um ambiente novo de trabalho, existe uma ansiedade por parte dele sobre a sua atuação pedagógica nesse novo ambiente. Logo que foi proposta a ideia de estudos coletivos e levantamento de problemáticas para serem discutidas pelos professores, fica clara a preocupação da equipe gestora com essas ansiedades dos novos docentes.

Os momentos de formação, os quais fizeram parte desta pesquisa-ação serviram para refletirmos sobre nosso papel frente a educação das crianças e possibilitou reflexões sobre formas de organizar tempos e espaços educativos a fim de alcançarmos nossos objetivos com as crianças. Além disso, esses encontros serviram para elencar as diferentes problemáticas enfrentadas pelos docentes, dentre as quais surgiu o problema: "Quais vivências podem ser planejadas, considerando a participação das crianças, a fim resultarem na aprendizagem de conceitos matemáticos dentro de pressupostos da Pedagogia Freinet?".

Como resposta ao problema, constatou-se que há uma série de vivências que possibilitaram aprendizagens de conceitos matemáticas. Aqui, são destacadas ações que envolveram o planejamento do professor (como na proposição de brincadeiras e registros numéricos ou na organização do ateliê da matemática) e outras ações que surgiram por iniciativa das crianças (como na iniciativa de João ao compartilhar a sua "tabela de números" ou na confecção do jogo da memória de Isabela)

Ao longo do ano letivo percebeu-se que as brincadeiras escolhidas pelas crianças ou sugeridas pelo professor, os jogos, fazeres cotidianos e sugestões espontâneas das crianças mostraram-se como bons recursos para aprender matemática e outros tantos saberes intrínsecos a essas práticas. Porém, há de se ressaltar que essas vivências se tornaram situações de aprendizagem com estimulo ao protagonismo das crianças nessas práticas. Não houve nenhuma tarefa imposta aos pequenos, mas vários convites às vivências junto do professor e dos demais 
colegas da turma para o tateamento experimental. Além disso, as situações que geraram aprendizagens matemáticas foram ampliadas com discussões em roda, envolvimento de outras crianças, indicando necessidades de registro numéricos etc.

O tateamento experimental com conhecimentos matemáticos em diferentes momentos da rotina foram objeto de reflexão dos professores e, a partir das discussões em grupo, chegamos aos possíveis planejamentos que sugeriram caminhos para aprendizagem de matemática pelas crianças.

Tais aprendizagens ocorreram a partir de discussões sobre a necessidade de organização da sala, brincadeiras propostas para as crianças, ou por iniciativas dos pequenos que foram ampliadas pelo professor. Desta forma, mostra-se nesta pesquisa caminhos para aprender matemática na Educação Infantil que vão além de atividades tradicionais, como circular numerais em treinos motores, contagem das crianças sem um significado conhecido pelos pequenos, práticas de memorização desprovidas de um sentido etc.

Durante o levantamento teórico, percebe-se que a Educação Infantil é um campo que precisa de maior enfoque investigativo quando se fala em aprendizagem de matemática. Nesse sentido, esta pesquisa visa contribuir para que essas discussões sejam estimuladas dentro das instituições que educam crianças.

Além disso, a metodologia de pesquisa-ação mostrou-se como uma forma de organizar os momentos de estudo dentro dos ambientes educacionais. Ela se mostrou bastante relevante para organizar as práticas de estudos todos os docentes e serviu para levantar outras discussões que, apensar de não terem sido abordadas nesse artigo, tiveram bastante relevância para as práticas pedagógicas com as crianças.

É relevante destacar, também, a necessidade das instituições educacionais se mobilizarem para estudarem e responderem os problemas pelos quais anseiam resolver. $\mathrm{O}$ estudo aqui descrito mostra-se como um exemplo que pode servir de inspiração para organização de momentos de formação continuada dentro de instituições de Educação Infantil. Os encontros formativos descritos neste texto propiciaram momentos nos quais os professores tiveram oportunidade de estudar os próprios anseios referentes as suas práticas. Este é um caminho que se mostrou bastante eficiente para responder às necessidades do professor que escreveu este texto e estimulou movimentos de práxis pedagógica ao longo de vários momentos de sua prática. 


\section{REFERÊNCIAS}

BRASIL, Ministério da Educação. Secretaria de Educação Básica. Diretrizes curriculares nacionais para a Educação Infantil / Secretaria de Educação Básica. - Brasília: MEC, SEB, 2010 .

BRASIL, MINISTÉRIO DA EDUCAÇÃO (MEC). Base Nacional Comum Curricular. Proposta preliminar ( $3^{\mathrm{a}}$ versão). Abr. 2017.

CAMPINAS, Diretrizes Curriculares da Educação Infantil: Um processo de reflexão e ação. Secretaria Municipal de Educação, Campinas, 2014.

COUTINHO, Clara Pereira; SOUSA, Adão; DIAS, Anabela; BESSA, Fátima; FERREIRA, Maria José Rodrigues Cunha; VIEIRA, Sandra Regina (2009). Investigação-acção: metodologia preferencial nas práticas educativas. Revista Psicologia, Educação e Cultura, $13: 2$, pp. 355- 379.

FRANCO, Maria Amélia Santoro. A pedagogia da pesquisa-Ação. Educação e Pesquisa, São Paulo, SP, v. 31, n. 03, p. 483-502. set./dez.2005.

FREINET, Élise. O itinerário de Célestin Freinet: a livre expressão na pedagogia de Freinet. Rio de Janeiro: Francisco Alves, 1979.

FREINET, Célestin. Pedagogia do Bom Senso. São Paulo: Martins Fontes, 1996.

GARNICA, Antonio Vicente. História Oral e educação Matemática. In: BORBA, Marcelo . de Carvalho.; ARAÚJO, Jussara de Loiola (Org.) Pesquisa Qualitativa em Educação Matemática. Belo Horizonte: Autêntica, 2004. p.1-18.

GUNTHER, Hartmut. Pesquisa qualitativa versus pesquisa quantitativa: esta é a questão? Psicologia: Teoria e Pesquisa, Brasília, v. 22, n. 2, p. 201-210, 2006.

LORENZATO, Sérgio. Educação Infantil e Percepção Matemática. Campinas: Autores Associados, 2008.

SAMPAIO, Rosa Maria Whitaker. Freinet: evolução histórica e atualidades. São Paulo: Editora Scipione, 2006.

SMOLE, Kátia; DINIZ, Maria Ignez S. V.; CANDIDO, Patrícia T. Brincadeiras infantis nas aulas de Matemática. Porto Alegre: Artmed, 2000.

SMOLE, Kátia. A matemática na educação infantil. a teoria as inteligências múltiplas na prática escolar. Porto Alegre: Artmed, 2003.

THIOLLENT, Michel. Metodologia da pesquisa-ação. 7ª ed. São Paulo: Cortez, 1996.

TORTORA, Evandro. O Lugar da Matemática na Educação Infantil: um estudo sobre as atitudes e crenças de autoeficácia das professoras no trabalho com as crianças. 2019. 222 f. Tese (Doutorado em Educação para Ciência) - Faculdade de Ciências, Universidade 
Revista Prática Docente (RPD)

ISSN: 2526-2149

Estadual Paulista - UNESP, Bauru. Disponível em:

https://repositorio.unesp.br/handle/11449/191442. Acesso em: 12 fev. 2020.

Recebido em: 24 de maio de 2020 .

Aprovado em: 4 de julho de 2020. 